\title{
“Please Draw Me a Face...” Atypical Face Mental Concept in Autism
}

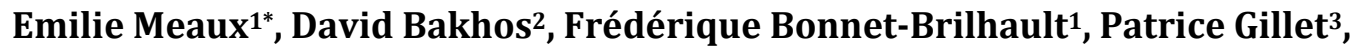 \\ Emmanuel Lescanne4, Catherine Barthélémy1, Magali Batty ${ }^{1}$ \\ ${ }^{1}$ UMRS Imagerie et Cerveau, Inserm U930 Equipe 1, CNRS ERL 3106, Université François Rabelais de Tours, \\ CHRU de Tours, Tours, France \\ ${ }^{2}$ Unité Pédiatrique d'ORL et CCF, Centre Hospitalier Régional Universitaire de Tours, Université François \\ Rabelais de Tours, CHRU de Tours, Tours, France \\ ${ }^{3}$ Université François Rabelais de Tours, CHRU de Tours, Tours, France \\ ${ }^{4}$ Service d'ORL et CCF Pédiatrique, CHU de Tours Gatien-de-Clocheville, Université François Rabelais de Tours, \\ Tours, France \\ Email: ${ }^{*}$ Emilie.Meaux@unige.ch
}

Received 16 May 2014; revised 12 June 2014; accepted 5 July 2014

Copyright (C) 2014 by authors and Scientific Research Publishing Inc.

This work is licensed under the Creative Commons Attribution International License (CC BY).

http://creativecommons.org/licenses/by/4.0/

(c) (i) Open Access

\begin{abstract}
Autism is a severe neurodevelopmental disorder characterized by early manifestations of social difficulties and atypical sensory-based behaviors. As faces are essential for social interaction, they have been widely investigated in autism, revealing disruptions in face processing. Cognitive theories argue that people with autism process the world differently, showing a processing bias for local information. However, the literature currently neglects the mental representation of faces, or face concept, in people with ASD. The current study sought to establish how young children with ASD "see" a human face. A key question is whether this face concept is a function of cognitive style and/or sensory impairment. By comparing simple face drawings in young children with ASD, with those of deaf children and controls, we highlight an atypical face concept in ASD that does not show, however, global processing deficits: face drawing presents a preserved overall configuration. The atypical face drawings in children with ASD showed similarities with those of deaf children: eyes were not an essential feature, whereas a marked interest for ears and non-facial external features (accessories, body parts) was shown. These findings suggest that the face mental concept in ASD may be impacted by sensory processing deficits.
\end{abstract}

\section{Keywords}

Autism, Face Representation, Drawing, Sensory Abnormalities, Cognitive Style

\footnotetext{
${ }^{*}$ Corresponding author.
}

How to cite this paper: Meaux, E., Bakhos, D., Bonnet-Brilhault, F., Gillet, P., Lescanne, E., Barthélémy, C., \& Batty, M. (2014). "Please Draw Me a Face..." Atypical Face Mental Concept in Autism. Psychology, 5, 1392-1403. 


\section{Introduction}

Autism spectrum disorders (ASD) are severe developmental conditions characterized clinically by two areas of symptoms, including deficits in social communication. Atypical sensory-based behaviors are also a part of the new diagnostic criteria (DSM-V, 2013), over 96\% of children with ASD reporting hyper and/or hypo-reactivity to sensory inputs or unusual interest in sensory aspects of the environment (Marco, Hinkley, Hill, \& Nagarajan, 2011). Similar to the wide-range of spectrum severity found for communication and social deficits, sensory behavioural differences also range from mild to severe, concern all sensory modalities, and affect unimodal stimuli processing as well as multisensory integration (Blakemore et al., 2006; Crane, Goddard, \& Pring, 2009; Leekam, Nieto, Libby, Wing, \& Gould, 2007; Minshew, Sweeney, \& Luna, 2002; Tomchek \& Dunn, 2007). Several studies suggested that these basic sensory atypicalities may be considered as a part of the mechanisms driving cognitive and social impairments observed in ASD (Ashwin, Ashwin, Rhydderch, Howells, \& Baron-Cohen, 2009; Batty, Meaux, Wittemeyer, Roge, \& Taylor, 2011; Bertone, Mottron, Jelenic, \& Faubert, 2005; Bruneau, Bonnet-Brilhault, Gomot, Adrien, \& Barthelemy, 2003; Scherf, Luna, Kimchi, Minshew, \& Behrmann, 2008). In this view, a possible cascade from sensory to social inputs and outputs should be taken into account when studying socio-communicative abnormalities in ASD.

One way of investigating social communication deficits in ASD is through human faces. For typically developing (TD) people, faces constitute powerful and socially relevant stimuli as they provide information about age, sex, emotion and mental states of others. Based on gaze direction and lip reading, faces also play an important role in communication (Itier \& Batty, 2009). Because faces are highly social, their perception involves mechanisms that differ from those that underlie the perception of objects (Farah, 1996). Typically, adults' expertise in face perception induces processing based on the configuration of the elementary features of the face (called configural processing) and on their integration in a global percept (called holistic processing) at the expense of details (called featural or local processing). In ASD, previous neuropsychological, developmental and neuroimaging observations reported disruption of face processing, face recognition and/or face exploration (Arkush, Smith-Collins, Fiorentini, \& Skuse, 2013; Batty et al., 2011; Dalton et al., 2005; Klin, Jones, Schultz, Volkmar, \& Cohen, 2002; Tottenham et al., 2013; Wilson, Pascalis, \& Blades, 2007). The phenomena associated with atypical performance on face tasks have been addressed by several cognitive theories (Happe \& Booth, 2008), which contend that people with ASD process the world differently: the weak central coherence (WCC) hypothesis (Dakin \& Frith, 2005; Happe \& Frith, 2006) and the enhanced perceptual function (EPF) hypothesis (Mottron \& Burack, 2001; Mottron, Dawson, Soulieres, Hubert, \& Burack, 2006). The WCC theory argues that individuals with ASD show a processing bias for local information or "can't see the forest for the trees" (Happe \& Booth, 2008; Happe \& Frith, 2006) and a relative failure to extract global meaning. In contrast to WCC, EPF does not posit a failure of global processing but proposes that in autism enhanced processing of local elements is facilitated. These models suggest that ASD people may favor featural encoding of faces, at the expense of a holistic/configural face perception (Deruelle, Rondan, Gepner, \& Tardif, 2004; Faja, Webb, Merkle, Aylward, \& Dawson, 2009; Teunisse \& de Gelder, 2003). These differences in perceiving faces have been strongly associated to the social aspect of the autistic symptomatology.

However, it is a challenge to interpret whether social communication symptoms result from this peculiar cognitive style (local bias), or are secondary to atypical primary sensory processing. To address this concern, an investigational track would compare the way people with ASD process faces to the way people suffering from sensory impairment do. For example, in early sensory deprivation such as like congenital deafness, social communication is hugely impacted by the absence of hearing and despite compensatory strategies (sign language and cochlear implants), processing of sensory inputs and their integration are severely disrupted. Moreover, and in contrast to ASD, no specific cognitive style has been identified in deaf people; social interactions are impacted by language delay but they are not related to local/global processing and/or face processing abnormalities. Auditory atypicalities are also a common feature in individuals across the autistic spectrum. Additionally, 50\% of individuals with ASD never acquire language. Among those who do, language abilities range from clinically normal to various degrees of impairment (Boucher et al., 2012). Thus sensory abnormalities observed in ASD and deaf people and their comparison yields an interesting approach to the conceptual representation of faces, which are invaluable to social communication.

Amid the large literature describing face processing in ASD, a neglected dimension is face representation. The literature reports some exceptional competence in the graphic field in ASD, but few studies have investi- 
gated drawing style, focusing on visual realism and expressivity (Booth, Charlton, Hughes, \& Happe, 2003; Eames \& Cow, 1994; Fein, Lucci, \& Waterhouse, 1990; Jolley, O’Kelly, Barlow, \& Jarrold, 2013; Lee \& Hobson, 2006; Mottron, Belleville, \& Menard, 1999; Sheppard, Mitchell, \& Ropar, 2008) and, to our knowledge, only one case study reported human face drawing (Cox \& Eames, 1999). This orphan study reported the drawings of two artistically gifted young people with autism and emphasized that one of them drew human faces, concentrating on the drawing technique of tonal contrasts. However, although less studied, face drawing may yield important information on how faces are conceptualized. Asking for a simple drawing of a face requires a transfer of how the individual "sees" a face. This mental representation is constructed from our elementary sensory world as well as the influence of the cognitive perceptual strategies we use. In other words, the representation we create of a face is largely defined by the way we encode it, not only by the way it really looks. It is not possible to encode the infinite gradations in colour and light, or the enormous array of details of a face and thus much information must be omitted, leading to attention to the most valuable information. According to this view, previous research suggests that individual differences in visual perceptual processing underpin differences in realistic drawing ability (Cohen, 2005; Cohen \& Bennett, 1997; Kozbelt, Seidel, El Bassiouny, Mark, \& Owen, 2010; Ostrofsky, Kozbelt, \& Seidel, 2012) and some studies have already drawn attention to local-global processing of drawings in ASD (Drake, Redash, Coleman, Haimson, \& Winner, 2010; Drake \& Winner, 2012; Mottron, Belleville, \& Menard, 1999; Pring, Ryder, Crane, \& Hermelin, 2010). Exploring potential correlates of drawing and perceptual expertise in ASD and non-ASD artists or TD people, these studies provided support for the notion that an ability to record and manipulate the details of the visual environment, i.e., local encoding, may be associated with better ability to draw. Moreover, the relation between local processing and drawing ability was found to be independent of individual differences in nonverbal IQ and artistic ability (Chamberlain, McManus, Riley, Rankin, \& Brunswick, 2013). In this context, drawing and mental representation seem to be a reliable and underutilised tool to address sensory and cognitive aspects of face processing in ASD, although has been used in TD children (Coulbeau, Royer, Brouziyne, Dosseville, \& Molinaro, 2008) as well as in epilepsy (Gomes-Correia, 2000), prosopagnosia (Klein et al., 2008)_and other neurological diseases (Emery, 2004).

Using a drawing task, the current study sought to establish how young children with ASD "see" a human face. A pertinent question in this domain is whether the mental representation of faces in ASD is a function of cognitive style and/or sensory impairment. Thus, to disentangle sensory from cognitive impact on face representation, we compared this face concept to that of age-matched typically developing (TD) children and deaf children with cochlear implants (CI). Partially deaf participants provide a unique opportunity to examine the influence of early auditory deprivation on face perception and furnish a first step to investigate the impact of sensory and cognitive factors on social representation in ASD. As ASD people are known to present both face processing and sensory impairments, we hypothesised that face mental representation would be disrupted. In the same vein, if deaf children exhibit a comparable representation of faces as ASD children, it would suggest that impairments in face processing in ASD may be more impacted by primary sensory deficits than by local/global abnormalities.

\section{Method}

\subsection{Participants}

Thirty-three children divided into three groups were tested.

The first group included 11 children (9 boys) with Autism Spectrum Disorders (ASD), all involved in a day care hospital. Children had been diagnosed by a fully qualified clinical child psychologist according to the DSM IV (APA, 2000). The diagnosis was confirmed by ADI and/or ADOS. The Childhood Autism Rating Scale (CARS) (Schopler, Rechler, \& Rochen Renner, 1988) was also completed, and scores ranged between 29 and 35 across the sample (mean $=31.2 \pm 1.9$ ). From the Revised Behavior Summarized Evaluation scale (BSE-R) (Barthelemy et al., 1997), bizarre responses to auditory stimuli (item 24) were evaluated, confirming that auditory abnormalities were observed from sometimes to always in all the participants with ASD. This group presented a mean chronological age of $9 \mathrm{y} 2 \mathrm{~m}( \pm 14.7 \mathrm{~m})$ and a mean developmental age of $7 \mathrm{y} 9 \mathrm{~m}( \pm 31.6 \mathrm{~m})$ measured by EDEI-R (normed French intellectual assessment tool which include subtests like vocabulary, word reasoning, block design, picture concepts assessment) (Perron-Borelli, 1996) (mean QDv = $76.3 \pm 21.6$; mean QDnv $=96.3 \pm 21.5$; mean $\mathrm{QD}=86.3 \pm 14.6$ ). No child in the autistic group had savant skills in drawing.

The second group included 11 congenitally deaf children with cochlear implants (CI) as hearing aids (2 boys) with a mean chronological age of 7y9m $( \pm 16.8 \mathrm{~m})$. Psychological assessments revealed no general developmen- 
tal delay in this group (EDEI-R; Brunet-Lezine-R). The children were recruited from the paediatric otolaryngology unit of Tours hospital. Children had received a CI between $1 \mathrm{y} 3 \mathrm{~m}$ and $5 \mathrm{y} 5 \mathrm{~m}$ (mean $=3 \mathrm{y} 7 \mathrm{~m} \pm 2 \mathrm{y} 2 \mathrm{~m}$ ) and had at least 1year experience with the CI (mean $=4 \mathrm{y} 3 \mathrm{~m} \pm 2 \mathrm{y} 6 \mathrm{~m}$ ). Since their implantation, the children had partial access to auditory information (mean absolute threshold of hearing for a frequency of $1000 \mathrm{~Hz}=34.4 \mathrm{~dB} \pm$ 4.17; MAIS $=36 / 40 \pm 10.15$ ). Moreover, communication was helped by the use of French sign language (LSF) for 7 of these children. Thus, although audition was still a highly affected sense in this second group, their abilities allowed them to be integrated in normal primary schools.

The autistic and the deaf groups were matched on developmental age to a control group consisting of typically developing (TD) children (8 boys; mean chronological/developmental age of 7y7m $\pm 6.2 \mathrm{~m}$ ).

The three populations did not differ in developmental age (n.s; Kruskal-Wallis, $\mathrm{H}=0.75 ; p=0.68$ ). None of the TD participants had a history of behavioural, psychiatric, neurological or sensory disorders. Prior to inclusion, the purpose of the study was explained and informed consent was obtained from the parents, and verbal assent from the children.

\subsection{Materials}

Paper, colouring pencils, felt-tip pens, ballpoint pens and erasers were freely available.

\subsection{Procedure}

To assess face mental representation, we asked children to draw a face, without giving any particular indications or time limitation. While the child was drawing, we wrote down the choice of the facial features represented and its position in the order of their drawings. Ten elements were investigated: outline of face, eyes, nose, mouth, hair, pupils, eyelashes, eye brows, ears and non-face elements. For non-face elements, we also specified what kind of element was drawn: for example, glasses or jewellery (accessories) and/or neck or torso (other body parts). The number of these elements represented was also quantified. Statistical analyses consisted of non-parametric tests: to assess if one element was more or less represented in the three groups, we used a Chi ${ }^{2}$ test; a Kruskal-Wallis test was used to evaluate if the order of representation of the various features differed between the groups.

\section{Results}

\subsection{Face Features Drawn}

When asking children to draw a face, the children from the 3 groups drew the face outline, eyes and mouth (see Figure 1(a)). However, TD children more often drew eye details compared to the deaf children (pupils: $\chi^{2}(1)=$ 4.28, $p=0.038$; eyelashes: $\chi^{2}(1)=4.53, p=0.033$ ) and ASD children (pupils: $\chi^{2}(1)=5.72, p=0.016$; eyelashes: $\left.\chi^{2}(1)=6.76, p=0.009\right)(p<0.01)$, who represented eyes with simple dots. More children with ASD drew ears than TD children $(45.5 \%$ vs. $27.3 \%)\left(\chi^{2}(1)=4.10, p=0.042\right)$. This propensity to draw ears was even stronger in the deaf children who always drew them $\left(100 \%, \chi^{2}(1)=7.28, p=0.007\right.$, Figure $\left.1(b)\right)$. While the task required drawing a face, numerous sketches also included elements that are not part of the face (such as other body parts or accessories). All the children with ASD (100\%) and $82 \%$ of deaf children drew at least one non-face element whereas only $54.5 \%$ of TD children $\operatorname{did}\left(\chi^{2}(2)=13.35, p=0.001\right)$. Moreover, children with ASD were also more insistent on including these non-face elements than the others groups. For example, while TD children drew at most one or two non-face elements, ASD children represented up to 5 non-face elements in one drawing (Figure $1(b))$.

\subsection{Timing Course of the Drawing}

The order in which the different facial features were drawn revealed a different strategy across the three groups. Although most of the children started their drawing with the outline ( 90\%), depending on their clinical status the order of representation of facial features varied (Figure 1(c)). The statistical analyses did not reveal a significant difference of time course for the representation of eyes, mouth and nose but showed that ears $(\mathrm{H}=9.36$; $p=0.014)$ and non-face elements $(\mathrm{H}=5.99 ; p=0.023)$ were drawn in different orders for the three groups. $18.2 \%$ of children with ASD drew ears in $2^{\text {nd }}$ position whereas deaf children started to draw ears in $4^{\text {th }}$ position (27.3\%) 

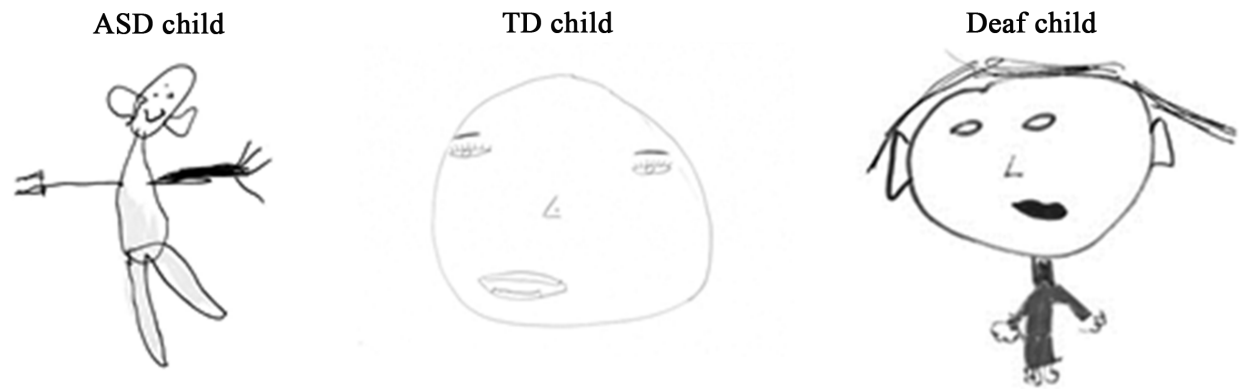

(a)

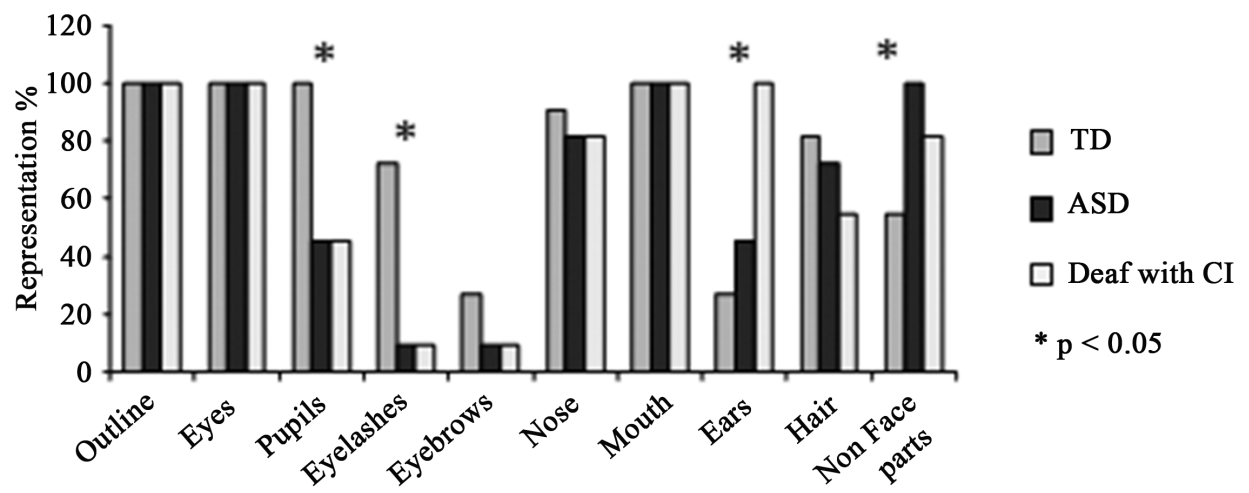

(b)
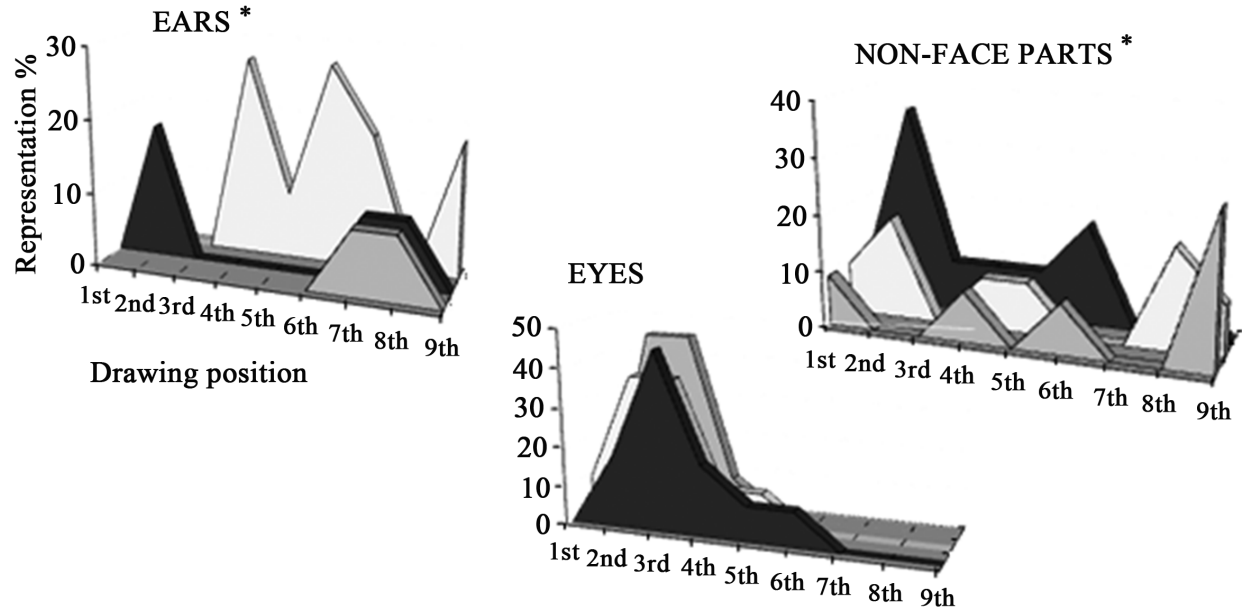

(c)

Figure 1. (a) Examples of children's drawings. Differences between face representation in ASD children, TD children and deaf children, is demonstrated by an example from each of the groups. TD children focused on representation of central facial features (eyes, nose and mouth were drawn accurately and in detail) whereas ASD and deaf children tended to use only dots to represent central facial information and emphasized ears and external features; (b) Percentages of children who drew the different features for each group. Statistical analyses revealed that children with ASD and deaf children presented the same propensity to avoid eye details and to prefer ears and external facial features in drawing, compared to TD children who favoured the internal facial features; (c) Order of representation of different facial features. When looking at facial features' order, the three groups of children did not organize their drawings in the same way: ASD children and deaf children began with elements which TD children used to complete their drawings (ears and non-face parts). We note a different timing for representing ears according to children's clinical status: ASD children drew ears in $2^{\text {nd }}$ position whereas deaf children with CI started to draw ears in $4^{\text {th }}$ position and TD children who included this feature, did so at the end of their drawing. 
while TD children who included this feature (18.2\%) did so at the end of their drawing $\left(7^{\text {th }}\right.$ or $8^{\text {th }}$ position). Similarly, most ASD and deaf children represented non-face elements at the beginning of their drawing just after the face outline, whereas most of the TD children who drew these non-face features did so at the end.

Thus, the choice of facial features drawn and the time course of their representation were related to clinical status.

\section{Discussion}

\subsection{Results Summary}

First, our results highlight a preserved overall configuration of face concept in ASD. However, eyes were not an essential feature in the human face concept for autistic children, whereas they clearly showed a surprising interest for external features and environmental context (ears, accessories and other body parts). These same atypical propensities during face drawing in autism and in partially deaf children with cochlear implants were observed.

\subsection{A Preserved Face Configuration}

By comparing face drawings in young children with ASD, deaf children and controls, we found an atypical face concept in ASD that did not reflect the widely discussed concept-independent features of images or the global/ configural processing deficit. Here, like deaf and TD children, the general face outline was drawn by all the children with ASD first and they drew eyes above nose above mouth. Although the order of drawing internal features was slightly different, all the core features of the face were represented in the correct place, suggesting that the overall configuration of the face is preserved in their face concept. The fact that children with ASD were able to accurately draw a face in the right configuration inside a previously drawn face outline is also consistent with a preserved global approach; all face information being integrated in a coherent whole. However, children with ASD present a marked interest for elements external to the face (accessories and other body parts were more often drawn), suggesting greater attention to environmental context. These results could be interpreted as a tendency towards global, not local, strategy during face drawing. ASD children did present an intact, coherent facet, characteristic of the TD population. These results are in contrast to suggestions of relations between ASD drawing style and local processing biases (Drake et al., 2010; Drake \& Winner, 2012; Mottron \& Belleville, 1993; Mottron et al., 1999; Pring et al., 2010). Some authors proposed a strategy referred to as "construction by local progression” (Mottron \& Belleville, 1999, Drake \& Winner, 2012); the subjects did not sketch in the overall shape but instead began their drawings with a detail, adding contiguous elements. In other words, for Drake \& Winner (2012) an ASD participant "began at the top and worked his way down to the base" when drawing a still-life model. However, these previous works focused on copying the Rey Complex Figure, embedded figures and/or drawings of objects and non-objects. Moreover, 4/5 of these studies reported results from 1 to 5 subjects only. Thus, our data are the first to report specifically face drawing (not copying) in a group of children with ASD. Our findings suggest that the local bias exhibited in ASD does not affect face representation, and that their face mental concept is not governed by the strategy used to encode faces. In this context, we propose that impairments in social interactions in ASD may be impacted by primary sensory deficits rather than by a locally oriented approach of faces. Our data on children without ASD but with auditory impairments allowed us to corroborate this hypothesis, as deaf children and ASD children presented some similarities in their drawing preferences as well as differences compared to the TD group, especially toward the intriguing aspect of the representation of ears.

\subsection{Drawing of Ears}

Ears were drawn more often and earlier in the sequence in the ASD than in the TD children's drawings; this propensity was more pronounced in deaf children. This marked interest for ears could be interpreted as a link with auditory perception, a domain that is strongly affected in both autism (Boucher et al. 2012 for review) and deaf children. Early auditory deprivation as well as regular and intense auditory assessments and the daily sensation of the cochlear implant may generate an exaggerated and persistent attention toward ears which could explain this result in deaf children. In the same way, retrospective parental reports and witnesses from high functioning people with autism provide evidence for abnormal auditory responses (Grandin, 1992; Jackson, 2003; Jackson, 2002) which could be linked to the representation of ears during our face drawing task. Relative to TD children, ASD children have been described more often as being preoccupied with or agitated by noise (Lane, 
Young, Baker, Angley, 2010; Monville \& Nelson, 1994; Berkell, Malgeri, \& Streit, 1996; Rimland \& Edelson, 1994; Osterling \& Dawson, 1994), and as presented heightened auditory discrimination (Rosenhall, Nordin, Sandstrom, Ahlsen, \& Gillberg, 1999; Eigsti \& Fein, 2013), and auto-stimulation toward ears. Moreover, physiological studies also showed measurable differences in early auditory pathways in ASD, especially with increasingly complex stimuli (Marco et al., 2011). Thus, because of the deformation of their auditory world, the mental face concept of both deaf and ASD children may be affected giving to the ears a privileged position.

However, there is another possible interpretation of this strong interest for ears in ASD. Ears are the most static feature of a face and constitute a reassuring element in a face that can otherwise be variable and often in motion. The rapid visual-motion integration deficit hypothesis of autism proposed that major movementprocessing disorder from early in life of ASD individuals leads them to avoid rapid physical and biological movements (considered as aversive stimuli), thus disrupting social interaction secondarily (Gepner, 2004; Gepner, Deruelle, \& Grynfeltt, 2001; Gepner \& Mestre, 2002a; Gepner \& Mestre, 2002b). Finally, ears do not vary widely between individuals; we would not rely on ears to recognize someone. It is therefore possible that the preference shown for ears in children with ASD is also related to the constant and non-social aspect of this facial feature.

\subsection{Drawing of Non-Face Parts}

A second intriguing result was the drawing elements external to the face, body parts and accessories, that were less often and/or drawn later by TD children. It seems relevant that insistence on external elements of face in deaf children can be due to a quest for communication support despite sensory issues; drawing more external elements may reflect a compensatory strategy to assess social understanding by using the contribution of whole-body processing (Centelles, Assaiante, Etchegoyhen, Bouvard, \& Schmitz, 2012; Schneider et al., 2013). Body language and external physical characteristics carry huge non-verbal social cues that could be used to communicate with others. Under certain circumstances, as in auditory deprivation, these external elements of faces constitute a support that allows the child to grasp some social content. This strategy is also consistent with the use of sign language (employed by 7/11 deaf children) which requires a particular interest in body gestures. Auditory deprivation also leads to enhanced peripheral visual attention, whereas attention dedicated to the central visual field remains comparable as TD hearing individuals (Bavelier, Dye, \& Hauser, 2006; Bavelier et al., 2000; Neville \& Lawson, 1987; Proksch \& Bavelier, 2002). Thus, driven by an enhanced peripheral vision and using non-verbal cues for communication, deaf children may create their face concept in part on external nonfacial elements.

On the other hand in ASD, this special interest for non-face parts may be consider as a strategy to recognize others, to identify people they see in their daily life. Therefore, we suggest that, focusing on these elements, when deaf children look for a path to non-verbal communication, ASD children look for a way to recognize people who are essential for their daily life without interacting with them.

In contrast to this over-representation of non-face parts and external elements in ASD and deaf children, a specific pattern of internal facial features representation is also of interest.

\subsection{Drawing of Internal Facial Elements, Eyes and Mouth}

Eyes were extremely well detailed by TD children (eyebrows, pupils and eyeslashes), while they were represented by simple dots or circle by almost all the children with autism and deaf children. The eyes and eye details did not hold an important place in the drawings of ASD and deaf children, despite their powerful role for mediating emotional and social communication (Itier \& Batty, 2009). This finding is consistent with the fact that one of the components of abnormal social functioning in autism is an impaired ability to direct their gaze to other people's faces. Autistic individuals look less at faces than age-matched TD people (Trepagnier, Sebrechts, \& Peterson, 2002) and when they do so, exploratory ocular movements seem abnormal. Eye tracking studies of children and adults with autism have typically found abnormally infrequent gaze to the eyes and abnormally frequent gaze to other face parts, such as the mouth, or the hair line (Dalton et al., 2005; Klin et al., 2002; Neumann, Kohlbacher, Merkwirth, \& Lengauer, 2006; Speer, Cook, McMahon, \& Clark, 2007; Spezio, Adolphs, Hurley, \& Piven, 2007; van der Geest, Kemner, Verbaten, \& van Engeland, 2002). For example, Speer and colleagues reported that participants with autism differed from their typically developing peers for social-dynamic stimuli; fixation durations were decreased for eye regions and increased for body regions. Further, these fixation durations predicted scores on a measure of social responsiveness (Speer et al., 2007). In the same vein, a recent 
study reported that more the eyes conveyed social information the more autistic subjects performed ocular saccades away from the eyes (Spezio, Huang, Castelli, \& Adolphs, 2007), supporting the idea of an eye avoidance in autism (abnormality in eye contact, DSM IV). This is consistent with our findings that eyes were not well or realistically drawn by ASD children.

Deaf children also showed an under-representation of eyes compared to TD children but the reason may be different. In these children, poor drawing of eyes may be related to sign language processing. Signed languages use multiple processes including both manual and facial actions (Capak et al., 2008) and mouthings are considered as speech-derived mouth actions accompanying manual signs (Boyes Braem \& Sutton-Spence, 2001). In this context, drawing mouth (as well as other body parts) seems more relevant for deaf children who used sign language than focusing on the eyes: they need to rely on this internal facial feature for lip reading and/or sign language. Our result showed similar mouth representation in the 3 group. However, the mouth was represented with more details in the deaf group than in the ASD and TD groups, i.e., deaf children drew lips separately, as well as mouth's corners and embellished it with color. In accordance with this notion, eye-tracking studies showed that attention to mouths and hands (for beginning signers especially, which is the case in a child population) impact gaze fixation patterns during sign language comprehension (Capek et al., 2008; De Filippo \& Lansing, 2006; Emmorey, Thompson, \& Colvin, 2009; Muir \& Richardson, 2005). As an example, watching sign language video clips, deaf people are found to fixate mostly on the facial region of the signer to pick up small detailed movements associated with facial expression and mouth shapes. Thus, atypical representation of eyes in deaf children may support not avoidance for social cues but a preferential attention toward mouth and body elements. In other words, deaf children's face concept may be more in relation to their language than specific facial issues.

\subsection{Future Directions}

First, we believe that we have found fundamental, new results that raise questions and encourage further research in this unexplored aspect of face cognition in autism. Future studies will need to compare face drawing to visual processing of faces in a same population by assessing, for example, how it would be related to abilities during face recognition, face exploration, and/or gaze and emotion processing tasks. Future studies should also measure auditory as well as visual thresholds in the ASD children. We relied on the huge literature reporting auditory impairments in autism and on the BSE scale subscore, demonstrating auditory atypicalities in all of the children with ASD that were included. Also, our conclusions would have benefited from inclusion of non-face drawing to ensure that the global/configural approach of faces during face representation is specific to faces, although previous studies have already implicated a part-oriented approach to object and non-object drawings (Drake et al., 2010; Drake \& Winner, 2012; Kuschner, Bodner, \& Minshew, 2009; Mottron \& Belleville, 1993; Mottron et al., 1999; Pring et al., 2010; Tsatsanis et al., 2011). Finally, it would be interesting to investigate teaching effects on drawing popular stimuli. Children may have received feedback during their daily lives on how to draw certain common objects, including faces, which may interfere with the evaluation of their approach. Using the same task and asking for a spontaneous drawing of a less familiar object and comparing its representation to face concept would be relevant to isolate this instructional effect. However, not only were our data acquired in young children (for whom this teaching may be incomplete), ASD people also present general learning difficulties (for review see (O’Brien \& Pearson, 2004)) which may have prevented this factor to influence our data.

\section{Conclusion}

For the first time, this study probed specific abnormalities in face mental representation in a group of ASD children and showed that a simple drawing task yields very relevant information to evaluate this underutilised field of research. A preserved global/configural coherence of face representation in ASD, associated with the same atypical propensities to draw ears during face drawing in ASD and deaf children, suggests that sensory dysfunction more than cognitive abnormalities may govern face concept in autism. However, poorly detailed eyes drawing and the abundance of external non-facial elements in both ASD and deaf children also indicate that this face concept is strongly influenced by the atypical exploration and perception of face. In other words, it seems that the widely observed sensory impairments in ASD might contribute to social interaction difficulties, rather more than complex cognitive style (local bias). Finally, the fact that the procedure was very simple en- 
hances the accessibility of the task to a wide spectrum of autistic children and would allow its inclusion in classical clinical settings, as the task can be used as a sharing tool to develop social contact and communication.

\section{Acknowledgements}

Financial support was provided by the Orange Fundation [http://www.fondationorange.com/]. Most of all, we thank all the children for their time and effort spent participating in this study. We also thank Margot Taylor for her valuable help and comments. No conflict of interest had to be declared.

\section{References}

APA (2000). Diagnostic and Statistical Manual of Mental Disorders (DSM-IV). Washington DC: APA.

Arkush, L., Smith-Collins, A. P., Fiorentini, C., \& Skuse, D. H. (2013). Recognition of Face and Non-Face Stimuli in Autistic Spectrum Disorder. Autism Research. http://dx.doi.org/10.1002/aur.1318

Ashwin, E., Ashwin, C., Rhydderch, D., Howells, J., \& Baron-Cohen, S. (2009). Eagle-Eyed Visual Acuity: An Experimental Investigation of Enhanced Perception in Autism. Biological Psychiatry, 65, 17-21.

http://dx.doi.org/10.1016/j.biopsych.2008.06.012

Barthelemy, C., Roux, S., Adrien, J. L., Hameury, L., Guerin, P., Garreau, B., Fermanian, J., \& Lelord, G. (1997). Validation of the Revised Behavior Summarized Evaluation Scale. Journal of Autism and Developmental Disorders, 27, 139-153. http://dx.doi.org/10.1023/A:1025887723360

Batty, M., Meaux, E., Wittemeyer, K., Roge, B., \& Taylor, M. J. (2011). Early Processing of Emotional Faces in Children with Autism: An Event-Related Potential Study. Journal of Experimental Child Psychology, 109, 430-444. http://dx.doi.org/10.1016/j.jecp.2011.02.001

Bavelier, D., Dye, M. W., \& Hauser, P. C. (2006). Do Deaf Individuals See Better? Trends in Cognitive Sciences, 10, 512518. http://dx.doi.org/10.1016/j.tics.2006.09.006

Bavelier, D., Tomann, A., Hutton, C., Mitchell, T., Corina, D., Liu, G., \& Neville, H. (2000). Visual Attention to the Periphery Is Enhanced in Congenitally Deaf Individuals. The Journal of Neuroscience, 20, RC93.

Bertone, A., Mottron, L., Jelenic, P., \& Faubert, J. (2005). Enhanced and Diminished Visuo-Spatial Information Processing in Autism Depends on Stimulus Complexity. Brain, 128, 2430-2441. http://dx.doi.org/10.1093/brain/awh561

Blakemore, S. J., Tavassoli, T., Calo, S., Thomas, R. M., Catmur, C., Frith, U., \& Haggard, P. (2006). Tactile Sensitivity in Asperger Syndrome. Brain and Cognition, 61, 5-13. http://dx.doi.org/10.1016/j.bandc.2005.12.013

Booth, R., Charlton, R., Hughes, C., \& Happe, F. (2003). Disentangling Weak Coherence and Executive Dysfunction: Planning Drawing in Autism and Attention-Deficit/Hyperactivity Disorder. Philosophical Transactions of the Royal Society B, 358, 387-392. http://dx.doi.org/10.1098/rstb.2002.1204

Bruneau, N., Bonnet-Brilhault, F., Gomot, M., Adrien, J. L., \& Barthelemy, C. (2003). Cortical Auditory Processing and Communication in Children with Autism: Electrophysiological/Behavioral Relations. International Journal of Psychophysiology, 51, 17-25. http://dx.doi.org/10.1016/S0167-8760(03)00149-1

Capek, C. M., Waters, D., Woll, B., MacSweeney, M., Brammer, M. J., McGuire, P. K., David, A. S., \& Campbell, R. (2008). Hand and Mouth: Cortical Correlates of Lexical Processing in British Sign Language and Speechreading English. Journal of Cognitive Neuroscience, 20, 1220-1234. http://dx.doi.org/10.1162/jocn.2008.20084

Centelles, L., Assaiante, C., Etchegoyhen, K., Bouvard, M., \& Schmitz, C. (2012). Understanding Social Interaction in Children with Autism Spectrum Disorders: Does Whole-Body Motion Mean Anything to Them? L'Encéphale, 38, 232-240. http://dx.doi.org/10.1016/j.encep.2011.08.005

Chamberlain, R., McManus, I. C., Riley, H., Rankin, Q., \& Brunswick, N. (2013). Local Processing Enhancements Associated with Superior Observational Drawing Are Due to Enhanced Perceptual Functioning, Not Weak Central Coherence. Quarterly Journal of Experimental Psychology, 66, 1448-1466. http://dx.doi.org/10.1080/17470218.2012.750678

Cohen, D. J. (2005). Look Little, Look Often: The Influence of Gaze Frequency on Drawing Accuracy. Perception and Psychophysics, 67, 997-1009. http://dx.doi.org/10.3758/BF03193626

Cohen, D. J., \& Bennett, S. (1997). Why Can't Most People Draw What They See? Journal of Experimental Psychology: Human Perception and Performance, 23, 609-621. http://dx.doi.org/10.1037/0096-1523.23.3.609

Coulbeau, L., Royer, P., Brouziyne, M., Dosseville, F., \& Molinaro, C. (2008). Development of Children’s Mental Representations: Effects of Age, Sex, and School Experience. Perceptual and Motor Skills, 106, 241-250.

http://dx.doi.org/10.2466/pms.106.1.241-250

Cox, M., \& Eames, K. (1999). Contrasting Styles of Drawing in Gifted Individuals with Autism. Autism, 3, 397-409. http://dx.doi.org/10.1177/1362361399003004006 
Crane, L., Goddard, L., \& Pring, L. (2009). Sensory Processing in Adults with Autism Spectrum Disorders. Autism, 13, 215228. http://dx.doi.org/10.1177/1362361309103794

Dakin, S., \& Frith, U. (2005). Vagaries of Visual Perception in Autism. Neuron, 48, 497-507. http://dx.doi.org/10.1016/j.neuron.2005.10.018

Dalton, K. M., Nacewicz, B. M., Johnstone, T., Schaefer, H. S., Gernsbacher, M. A., Goldsmith, H. H., Alexander, A. L., \& Davidson, R. J. (2005). Gaze Fixation and the Neural Circuitry of Face Processing in Autism. Nature Neuroscience, 8 , 519-526.

De Filippo, C. L., \& Lansing, C. R. (2006). Eye Fixations of Deaf and Hearing Observers in Simultaneous Communication Perception. Ear \& Hearing, 27, 331-352. http://dx.doi.org/10.1097/01.aud.0000226248.45263.ad

Deruelle, C., Rondan, C., Gepner, B., \& Tardif, C. (2004). Spatial Frequency and Face Processing in Children with Autism and Asperger Syndrome. Journal of Autism and Developmental Disorders, 34, 199-210. http://dx.doi.org/10.1023/B:JADD.0000022610.09668.4c

Drake, J. E., \& Winner, E. (2012). Superior Visual Analysis and Imagery in an Autistic Child with Drawing Talent. Imagination, Cognition and Personality, 31, 9-29. http://dx.doi.org/10.2190/IC.31.1-2.d

Drake, J. E., Redash, A., Coleman, K., Haimson, J., \& Winner, E. (2010). “Autistic” Local Processing Bias also Found in Children Gifted in Realistic Drawing. Journal of Autism and Developmental Disorders, 40, 762-773. http://dx.doi.org/10.1007/s10803-009-0923-0

Eames, K., \& Cow, M. V. (1994). Visual Realism in the Drawing of Autistic, Down's Syndrome and Normal Children. British Journal of Developmental Psychology, 12, 235-239.

Emery, A. E. H. (2004). How Neurological Disease Can Affect an Artist’s Work. Practical Neurology, 4, 366-371.

Emmorey, K., Thompson, R., \& Colvin, R. (2009). Eye Gaze during Comprehension of American Sign Language by Native and Beginning Signers. Journal of Deaf Studies and Deaf Education, 14, 237-243. http://dx.doi.org/10.1093/deafed/enn037

Faja, S., Webb, S. J., Merkle, K., Aylward, E., \& Dawson, G. (2009). Brief Report: Face Configuration Accuracy and Processing Speed among Adults with High-Functioning Autism Spectrum Disorders. Journal of Autism and Developmental Disorders, 39, 532-538. http://dx.doi.org/10.1007/s10803-008-0635-x

Farah, M. J. (1996). Is Face Recognition “Special”? Evidence from Neuropsychology. Behavioural Brain Research, 76, 181189. http://dx.doi.org/10.1016/0166-4328(95)00198-0

Fein, D., Lucci, D., \& Waterhouse, L. (1990). Brief Report: Fragmented Drawings in Autistic Children. Journal of Autism and Developmental Disorders, 20, 263-269. http://dx.doi.org/10.1007/BF02284723

Gepner, B. (2004). Autism, Movement, and Facial Processing. American Journal of Psychiatry, 161, 1719-1720.

Gepner, B., \& Mestre, D. (2002a). Rapid Visual-Motion Integration Deficit in Autism. Trends in Cognitive Sciences, 6, 455. http://dx.doi.org/10.1016/S1364-6613(02)02004-1

Gepner, B., \& Mestre, D. R. (2002b). Brief Report: Postural Reactivity to Fast Visual Motion Differentiates Autistic from Children with Asperger Syndrome. Journal of Autism and Developmental Disorders, 32, 231-238. http://dx.doi.org/10.1023/A:1015410015859

Gepner, B., Deruelle, C., \& Grynfeltt, S. (2001). Motion and Emotion: A Novel Approach to the Study of Face Processing by Young Autistic Children. Journal of Autism and Developmental Disorders, 31, 37-45. http://dx.doi.org/10.1023/A:1005609629218

Gomes-Correia, A. (2000). Drawing of the Family and of the Human Figure: A Comparative Study between Children with Epilepsy and a Control Group. Revista de Neurologia, 31, 401-407.

Grandin, T. (1992). Calming Effects of Deep Touch Pressure in Patients with Autistic Disorder, College Students, and Animals. Journal of Child and Adolescent Psychopharmacology, 2, 63-72. http://dx.doi.org/10.1089/cap.1992.2.63

Happe, F., \& Booth, R. D. (2008). The Power of the Positive: Revisiting Weak Coherence in Autism Spectrum Disorders. Quarterly Journal of Experimental Psychology, 61, 50-63. http://dx.doi.org/10.1080/17470210701508731

Happe, F., \& Frith, U. (2006). The Weak Coherence Account: Detail-Focused Cognitive Style in Autism Spectrum Disorders. Journal of Autism and Developmental Disorders, 36, 5-25. http://dx.doi.org/10.1007/s10803-005-0039-0

Itier, R. J., \& Batty, M. (2009). Neural Bases of Eye and Gaze Processing: The Core of Social Cognition. Neuroscience \& Biobehavioral Reviews, 33, 843-863. http://dx.doi.org/10.1016/j.neubiorev.2009.02.004

Jackson, J. (2003). Multicoloured Mayhem: Parenting the Many Shades of Adolescents and Children with Autism, Asperger Syndrome and $A D / H D$. London: Jessica Kingsley.

Jackson, L. (2002). Freaks, Geeks and Asperger Syndrome: A User Guide to Adolescence. London: Jessica Kingsley.

Jolley, R. P., O’Kelly, R., Barlow, C. M., \& Jarrold, C. (2013). Expressive Drawing Ability in Children with Autism. British Journal of Developmental Psychology, 31, 143-149. http://dx.doi.org/10.1111/bjdp.12008 
Klein, S. B., Gabriel, R. H., Gangi, C. E., \& Robertson, T. E. (2008). Reflection on the Self: A Case Study of a Prosopagnosic Patient. Social Cognition, 26, 766-777. http://dx.doi.org/10.1521/soco.2008.26.6.766

Klin, A., Jones, W., Schultz, R., Volkmar, F., \& Cohen, D. (2002). Visual Fixation Patterns during Viewing of Naturalistic Social Situations as Predictors of Social Competence in Individuals with Autism. JAMA Psychiatry, 59, 809-816. http://dx.doi.org/10.1001/archpsyc.59.9.809

Kozbelt, A., Seidel, A., El Bassiouny, A., Mark, Y., \& Owen, D. R. (2010). Visual Selection Contributes to Artists’ Advantages in Realistic Drawing. Psychology of Aesthetics, Creativity and the Arts, 4, 93-102. http://dx.doi.org/10.1037/a0017657

Kuschner, E. S., Bodner, K. E., \& Minshew, N. J. (2009). Local vs. Global Approaches to Reproducing the Rey Osterrieth Complex Figure by Children, Adolescents, and Adults with High-Functioning Autism. Autism Research, 2, 348-358.

Lee, A., \& Hobson, R. P. (2006). Drawing Self and Others: How Do Children with Autism Differ from Those with Learning Difficulties? British Journal of Developmental Psychology, 24, 547-565. http://dx.doi.org/10.1348/026151005X49881

Leekam, S. R., Nieto, C., Libby, S. J., Wing, L., \& Gould, J. (2007). Describing the Sensory Abnormalities of Children and Adults with Autism. Journal of Autism and Developmental Disorders, 37, 894-910. http://dx.doi.org/10.1007/s10803-006-0218-7

Marco, E. J., Hinkley, L. B., Hill, S. S., \& Nagarajan, S. S. (2011). Sensory Processing in Autism: A Review of Neurophysiologic Findings. Pediatric Research, 69, 48R-54R. http://dx.doi.org/10.1203/PDR.0b013e3182130c54

Minshew, N. J., Sweeney, J., \& Luna, B. (2002). Autism as a Selective Disorder of Complex Information Processing and Underdevelopment of Neocortical Systems. Molecular Psychiatry, 7, S14-S15. http://dx.doi.org/10.1038/sj.mp.4001166

Mottron, L., \& Belleville, S. (1993). A Study of Perceptual Analysis in a High-Level Autistic Subject with Exceptional Graphic Abilities. Brain and Cognition, 23, 279-309. http://dx.doi.org/10.1006/brcg.1993.1060

Mottron, L., \& Burack, J. (2001). Enhanced Perceptual Functioning in the Development of Autism. In J. A. Burack, T. Charman, N. Yirmiya, \& P. R. Zelazo (Eds.), The Development of Autism: Perspectives from Theory and Research (pp. 131-148). Mahwah, NJ: Erlbaum.

Mottron, L., Belleville, S., \& Menard, E. (1999). Local Bias in Autistic Subjects as Evidenced by Graphic Tasks: Perceptual Hierarchization or Working Memory Deficit? Journal of Child Psychology and Psychiatry, 40, 743-755. http://dx.doi.org/10.1111/1469-7610.00490

Mottron, L., Dawson, M., Soulieres, I., Hubert, B., \& Burack, J. (2006). Enhanced Perceptual Functioning in Autism: An Update, and Eight Principles of Autistic Perception. Journal of Autism and Developmental Disorders, 36, 27-43. http://dx.doi.org/10.1007/s10803-005-0040-7

Muir, L. J., \& Richardson, I. E. (2005). Perception of Sign Language and Its Application to Visual Communications for Deaf People. Journal of Deaf Studies and Deaf Education, 10, 390-401. http://dx.doi.org/10.1093/deafed/eni037

Neumann, D., Kohlbacher, O., Merkwirth, C., \& Lengauer, T. (2006). A Fully Computational Model for Predicting Percutaneous Drug Absorption. Journal of Chemical Information and Modeling, 46, 424-429. http://dx.doi.org/10.1021/ci050332t

Neville, H. J., \& Lawson, D. S. (1987). Attention to Central and Peripheral Visual Space in a Movement Detection Task: An Event Related Potential and Behavioral Study. II. Congenitally Deaf Adults. Brain Research, 405, 268-283. http://dx.doi.org/10.1016/0006-8993(87)90296-4

O’Brien, G., \& Pearson, J. (2004). Autism and Learning Disability. Autism, 8, 125-140. http://dx.doi.org/10.1177/1362361304042718

Ostrofsky, J., Kozbelt, A., \& Seidel, A. (2012). Perceptual Constancies and Visual Selection as Predictors of Realistic Drawing Skill. Psychology of Aesthetics, Creativity and the Arts, 6, 124-136. http://dx.doi.org/10.1037/a0026384

Perron-Borelli, M. (1996). Echelle différentielle d'efficience intellectuelle. Forme révisée. Paris: Editions et Applications Psychologiques.

Pring, L., Ryder, N., Crane, L., \& Hermelin, B. (2010). Local and Global Processing in Savant Artists with Autism. Perception, 39, 1094-1103. http://dx.doi.org/10.1068/p6674

Proksch, J., \& Bavelier, D. (2002). Changes in the Spatial Distribution of Visual Attention after Early Deafness. Journal of Cognitive Neuroscience, 14, 687-701. http://dx.doi.org/10.1162/08989290260138591

Scherf, K. S., Luna, B., Kimchi, R., Minshew, N., \& Behrmann, M. (2008). Missing the Big Picture: Impaired Development of Global Shape Processing in Autism. Autism Research, 1, 114-129. http://dx.doi.org/10.1002/aur.17

Schneider, S., Christensen, A., Haussinger, F. B., Fallgatter, A. J., Giese, M. A., \& Ehlis, A. C. (2013). Show Me How You Walk and I Tell You How You Feel-A Functional Near-Infrared Spectroscopy Study on Emotion Perception Based on Human Gait. Neuroimage, 85, 380-390.

Schopler, E., Rechler, R. J., \& Rochen Renner, B. R. (1988). The Childhood Autism Rating Scale. Los Angeles, CA: Western Psychological Services. 
Sheppard, E., Mitchell, P., \& Ropar, D. (2008). Differences between Individuals with and without Autism in Copying Tasks: How Knowledge Interferes When Drawing Perspective. In C. Lange-Küttner, \& A. Vinter (Eds.), Drawing and the Non-Verbal Mind: A Life-Span Perspective (pp. 325-343). New York: Cambridge University Press.

Speer, L. L., Cook, A. E., McMahon, W. M., \& Clark, E. (2007). Face Processing in Children with Autism: Effects of Stimulus Contents and Type. Autism, 11, 265-277. http://dx.doi.org/10.1177/1362361307076925

Spezio, M. L., Adolphs, R., Hurley, R. S., \& Piven, J. (2007). Analysis of Face Gaze in Autism Using “Bubbles”. Neuropsychologia, 45, 144-151. http://dx.doi.org/10.1016/j.neuropsychologia.2006.04.027

Spezio, M. L., Huang, P. Y., Castelli, F., \& Adolphs, R. (2007). Amygdala Damage Impairs Eye Contact during Conversations with Real People. Journal of Neuroscience, 27, 3994-3997. http://dx.doi.org/10.1523/JNEUROSCI.3789-06.2007

Teunisse, J. P., \& de Gelder, B. (2003). Face Processing in Adolescents with Autistic Disorder: The Inversion and Composite Effects. Brain and Cognition, 52, 285-294. http://dx.doi.org/10.1016/S0278-2626(03)00042-3

Tomchek, S. D., \& Dunn, W. (2007). Sensory Processing in Children with and without Autism: A Comparative Study Using the Short Sensory Profile. American Journal of Occupational Therapy, 61, 190-200.

http://dx.doi.org/10.5014/ajot.61.2.190

Tottenham, N., Hertzig, M. E., Gillespie-Lynch, K., Gilhooly, T., Millner, A. J., \& Casey, B. J. (2013). Elevated Amygdala Response to Faces and Gaze Aversion in Autism Spectrum Disorder. Social Cognitive and Affective Neuroscience, 9, 106117.

Trepagnier, C., Sebrechts, M. M., \& Peterson, R. (2002). Atypical Face Gaze in Autism. CyberPsychology \& Behavior, 5, 213-217. http://dx.doi.org/10.1089/109493102760147204

Tsatsanis, K. D., Noens, I. L., Illmann, C. L., Pauls, D. L., Volkmar, F. R., Schultz, R. T., \& Klin, A. (2011). Managing Complexity: Impact of Organization and Processing Style on Nonverbal Memory in Autism Spectrum Disorders. Journal of Autism and Developmental Disorders, 41, 135-147. http://dx.doi.org/10.1007/s10803-010-1139-z

van der Geest, J. N., Kemner, C., Verbaten, M. N., \& van Engeland, H. (2002). Gaze Behavior of Children with Pervasive Developmental Disorder toward Human Faces: A Fixation Time Study. Journal of Child Psychology and Psychiatry, 43, 669-678. http://dx.doi.org/10.1111/1469-7610.00055

Wilson, R., Pascalis, O., \& Blades, M. (2007). Familiar Face Recognition in Children with Autism: The Differential Use of Inner and Outer Face Parts. Journal of Autism and Developmental Disorders, 37, 314-320.

http://dx.doi.org/10.1007/s10803-006-0169-z 
Scientific Research Publishing (SCIRP) is one of the largest Open Access journal publishers. It is currently publishing more than 200 open access, online, peer-reviewed journals covering a wide range of academic disciplines. SCIRP serves the worldwide academic communities and contributes to the progress and application of science with its publication.

Other selected journals from SCIRP are listed as below. Submit your manuscript to us via either submit@scirp.org or Online Submission Portal.
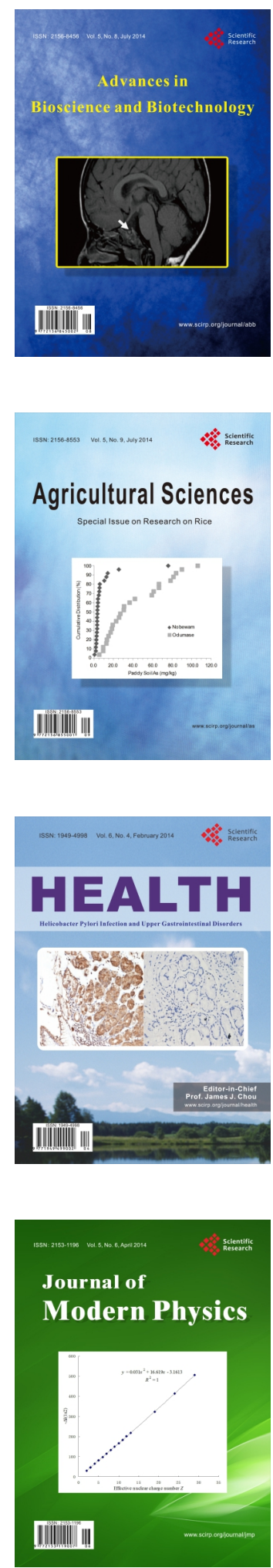
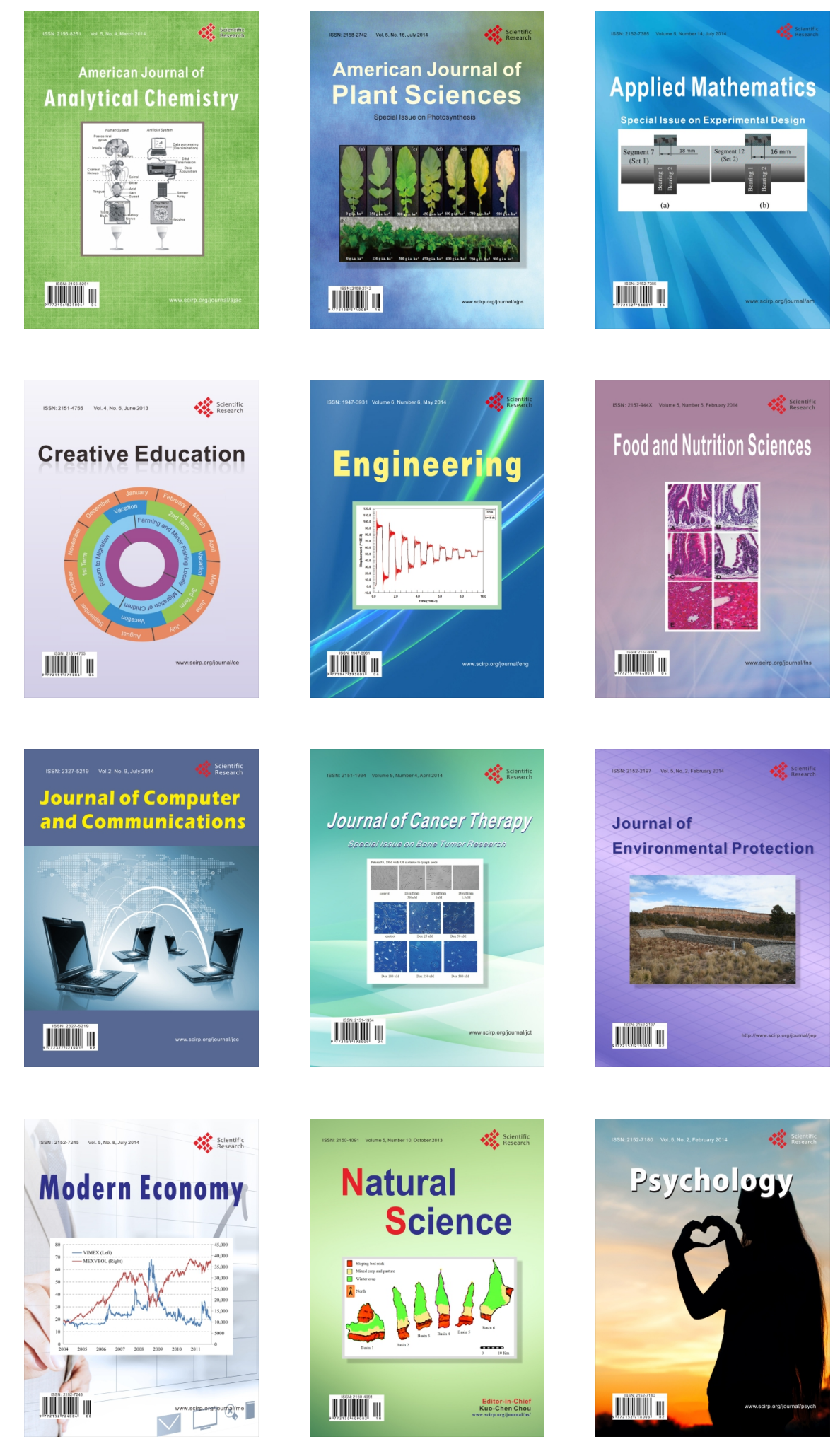